\title{
BULLETIN
}

\section{INTERNATIO NAL}

DFS

SOCII'TÉS DE LA CROIX-ROUGE

publié par le

COMITÉ INTERNATIONAL

FONDATEUR DE CETTE INSTITUTION
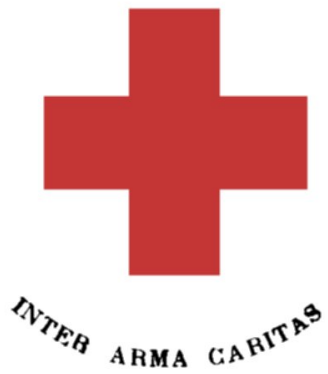

GENĖVE

IMFRIMERIE I. SOULLIER, CITÉ, 19-21

\section{8}




\section{COMITE INTERNATIONAL}

Pour adresse: M. Gustave Adon.

En hiver : rue de l'Athénée, 8 ; en été : à Colngny, près Genève

Les membres du Comité sont:

NII. Moynier, Gustave, Président d'honrieur de l'inslatut de droit internalional, Associé étranger de l'Institut rle France, Président.

Ador, Gustave, Conseiller national, $1^{\text {er }}$ Vice-Président.

Odler, Edouard, Ministre de Suisse à Saint-Pitersbourg, 2๑Vice-Président.

Moynier, Adolphe, Consul de Belgique, Trésorier.

D'Espine, Adolphe, Dr mėd., Professeur à l'Université, Secrélaire.

Favre, Camille, Colonel.

Ferrière, Frédéric, Dr-méd.

Gautier, Alfred, Professeur à l'Université et juge à la Cour de cassation. Naville, Edouard, Professeur à l'Université, Correspondant de l'Institut de France.

Rédaction et Administration du Bulletin: Des Gouttes, Paul, Docteur en droil, avocat, Corrate ie, 24 , Genève.

\section{ADRESSISS DES COMITÉS CENTIRAUX}

ALLEMAGNE. - Comité central des associations allemandes de la Croix-Honge. Roonstrasse, 9, à Berlin.

ARGENTINE (RÉPUBLIQUE). - Comilé central de la CroixRouge argentine. Moreno 3365, à Buenos-Ayres.

AUTRICHE - Société autrichienne de la Groix-Rouge. 'Tuchlauben, 6, à Vicune.

BADE. - Comité général de la Sociélé badoise de la CroixHouge. Gartenstrasse, 49, à Carlsruhe.

BAVIĖRE. - M. le Comte de Drechser, président du Comité central de la Société bavaroise de la Croix-Louge, à Mmich.

BELGIQUEx - Secrétariat général de la Croix-Lłonge de Belgique, Hòtel Raveustein, Salle VII, à Bruxelles.

BULGARIE. - M. J.-L. Guéchoff, président de la Société bulgare de la Croix-Rouge, à Sofia.

CONGO. - Association congolaise et africaine de la Croix. Rouge, rue de Namur, 12, à Bruxclles.

DANEMARK. - Société de la Críix-liouge (Det liode Kors), à Copenhague $K$.

ESPAGNE. - Société espagnole de la Groix-Rouge, Plaza del Progreso, 1, à Madrid.

ÉTATS-UNIS. - Central Committee of the American National Red Cross. Hoom 341, War Department, Washington D. C.

FRANCEx - Comité central de la Croix-Rouge française. Rue Matignon, 19, à Paris $8 \mathrm{e}$.

GRANDE BRETAGNE. - British Red Cross Society, 9, Victoria Street, Londres, S. W.

(Voir la suite à la troisième page de celte couverture, 